\title{
Effect of Storage Temperature on Bond Strength of a Self-Etch Adhesive System to Pulp Chamber Dentin
}

Nazmiye Donmez ${ }^{\mathrm{a}}$

Hale Arib

Sema Bellib

\section{ABSTRACT}

Objectives: The aim of this study was to evaluate the effect of storage temperature on bond strength of a self etching primer system to pulp chamber dentin.

Methods: SE Bond (Kuraray, JAPAN) adhesive system and Clearfil Photo Posterior (Kuraray, JAPAN) composite resin were used. Eight extracted caries-free human molar teeth were used. Access cavities were prepared through the pulp chamber, randomly distributed into 4 groups and prepared as follows: Group 1 (Control): SE Primer and SE Bond (SEB) were applied to the pulp chamber dentin according to the manufacturer's instructions, immediately after the delivery from the manufacturer and then the pulp chamber was restored with a resin restorative material. The primer agent of the following groups was stored in a refrigerator and kept at $4^{\circ} \mathrm{C}$. Group 2: restored with SEB, kept at $4^{\circ} \mathrm{C}$ refrigerator for 1 year, Group 3: restored with SEB kept at $23^{\circ} \mathrm{C}$ room temperature for 1 year and Group 4: restored with SEB kept at $40^{\circ} \mathrm{C}$ incubator for 1 year. After $24 \mathrm{hrs}$ the teeth were trimmed for microtensile bond testing and loaded to failure at $1 \mathrm{~mm} / \mathrm{min}$. Data were analyzed using one-way ANOVA and Duncan test $(P<.05)$.

Results: The results indicated that Group 4 showed lowest bond strength when compared to the others $(P<.05)$. No statistically significant difference was found among the other groups $(P>.05)$.

Conclusions: As a result of this study, it was concluded that increasing storing temperature or storing period decreases microtensile bond strength of a SEB system to pulp chamber dentin. (Eur J Dent 2009;3:314-317)

Key words: Storage temperature; Storage period; Bond strength; Self-etch adhesive; Chemical degradation of the adhesive.

\footnotetext{
a Specialist in Oral Health Hospital, Konya, Turkey.

b Department of Endodontics, Selcuk University,

Faculty of Dentistry, Konya, Turkey.

Corresponding author: Dr. Nazmiye DONMEZ Konya Agiz ve Dis Sagligi Merkezi

Dumlupinar mh. Selcuklu belediyesi yani 42060 Selçuklu, Konya, Turkey

Phone: + 903322515280

E-mail: nazmiyedonmezlahotmail.com
}

\section{INTRODUCTION}

A variety of adhesive systems are continuously being developed in order to produce good adhesion to dental substrates. Contemporary selfetching priming systems are one category of the simplified systems, which can demineralise and prime dentin simultaneously in one application. It no longer needs an "etch\&rinse" phase, which not 
only lessens clinical application time, but also significantly reduces technique-sensitivity or the risk of making errors during application and manipulation. Another important advantage of the self-etch approach is that infiltration of resin occurs simultaneously with the self-etching process, by which the risk of discrepancy between both processes is low or non-existent. ' Therefore self- etch adhesive systems have recently become popular in the clinic.

There are many factors in clinical or laboratory conditions affecting the performance of adhesive systems. Sometimes technique-sensitivity or material-related factors such as storage conditions to extend shelf life can also affect adhesive performance. ${ }^{2}$ Manufacturers usually recommend to keep the adhesive systems in a refrigerator and to use as soon as possible within the expiration date. Self-etching primer systems generally contain an acidic monomer (MDP), HEMA and water. Acidic monomers are hydrophobic, with an acidic radical such as a phosphoric or carboxyl radical at the end of their structure. ${ }^{3}$ For the acidity of the primer by the coexistence of the acidic monomer and water, HEMA is added to the primer solution. The acidic monomer demineralises the underlying dentin and penetrates into the demineralized collagen network. HEMA also promotes the permeation of monomers and bonding resin into demineralized collagen network, consistently to create a hybrid layer.

SE Bond adhesive contains HEMA as a wetting agent, Bis-GMA and acidic monomer MDP. ${ }^{3} \mathrm{HEMA}$, described as essential to promotion of adhesion because of its excellent wetting characteristics. ${ }^{4}$ Nakatsuka ${ }^{3}$ have been reported that both MDP and the tertiary amine are stable components, so the shelf life of SE Bond should be long and it's stable if refrigerated and even if at room temperature.

The aim of this study was to evaluate the effect of storage temperature of SE Bond on bond strength to pulp chamber dentin.

\section{MATERIALS AND METHODS}

\section{Materials}

In this study, a self-etch primer bonding system Clearfil SE Bond ISE Bond, Kuraray Medical Inc., Tokyo, JAPAN and a resin restorative material Clearfil Photo Posterior (Kuraray Medical Inc., Tokyo, JAPAN) were used. The ingredients of the materials are listed in Table 1.

\section{Sample preparation}

Eight extracted caries-free human molars stored in distilled water were used. After removal of calculus and soft-tissue debris, the access cavities through the pulp chamber were opened. The pulp tissues were carefully removed and the crowns were separated at the cemento-enamel junction using a high-speed bur under water-cooling. The teeth were then randomly distributed into 4 groups and prepared as follows:

Group 1(Control): Clearfil SE Primer and SE Bond (SE Bond, Kuraray Medical Inc., Tokyo, JAPAN) were applied to the pulp chamber dentin according to the manufacturer's instructions, immediately after the delivery from the manufacturer and then the pulp chamber dentin was restored with a composite resin material (Clearfil photo posterior, Kuraray Co., JAPAN).

The primer agent of the following groups was stored in a refrigerator and kept at $4^{\circ} \mathrm{C}$.

Group 2: The bonding system (SE Bond) used in this group was kept at $4^{\circ} \mathrm{C}$ for 1 year in a refrigerator. After treatment with SE Primer, bonding agent was applied, cured for $20 \mathrm{~s}$. and the pulp chamber was restored with the same resin composite material.

Group 3: The bonding system (SE Bond) used in this group was kept at $23^{\circ} \mathrm{C}$ for 1 year at room temperature. After treatment with SE Primer, bonding agent was applied, cured for $20 \mathrm{~s}$. and the pulp chamber was restored as in Group 1.

Group 4: The bonding system (SE Bond) used in this group was kept in $40^{\circ} \mathrm{C}$ incubator for 1 year.

Table 1. The ingredients and manufacturers of SE Bond.

\begin{tabular}{c|c|c|c}
\hline Adhesive systems & Primer(Self etching primer) & Adhesive resin & Manufacturer \\
\hline & MDP, HEMA, Hydrophilic & MDP, Bis - GMA, HEMA, & \\
& Hephobic dimethacrylate, & Kuraray, Osaka, \\
Clearfil SE Bond & dimethacrylate, CQ, N,N- Diethanol & CQ, N,N- Diethanol & JAPAN \\
& p-toluidine, Water & $p$ - toluidine, Silanated & \\
& & colloidal silica. & \\
\hline
\end{tabular}


After treatment with SE Primer, bonding agent was applied, cured for $20 \mathrm{~s}$. and the pulp chamber was restored as in Group 1.

The prepared specimens were kept in $37^{\circ} \mathrm{C}$ water for $24 \mathrm{hrs}$ before testing. After drying, the samples were fixed to a plexiglass block for testing procedures with sticky wax to permit creation of serial cross-sections $1 \mathrm{~mm}$ thick from the CEJ to apex using a Isomet saw (Buehler Ltd., Lake Bluff, IL). Non-trimming method ${ }^{5}$ was used to obtain sample sticks with cross-sectional areas of 1 $\mathrm{mm}^{2}$ (Figure 1) and microtensile bond strengths to root canal dentin were measured. Bond strength data was expressed in MPa and statistical analysis was performed using a One-way analysis of variance, followed by multiple comparisons were performed using a Duncan test at $5 \%$ level of significance.

\section{RESULTS}

The mean and standard deviation of microtensile bond strength values for the tested groups are shown in Table 2.

Statistically significant difference was found among Group 4 and the other groups $(P<.05)$. No significant difference was found among groups 1 , 2 and 3 ( $P>$.05).

Keeping the adhesive system in incubator for 1 year reduced the bond strength of the adhesive system $(P<.05)$. However keeping the adhesive system in refrigerator or room temperature did not effect bond strength when compared to the control group ( $P>$.05).

When the tested samples were evaluated under a stereomicroscope at X20 magnification, both tested groups showed mostly adhesive failure.

\section{DISCUSSION}

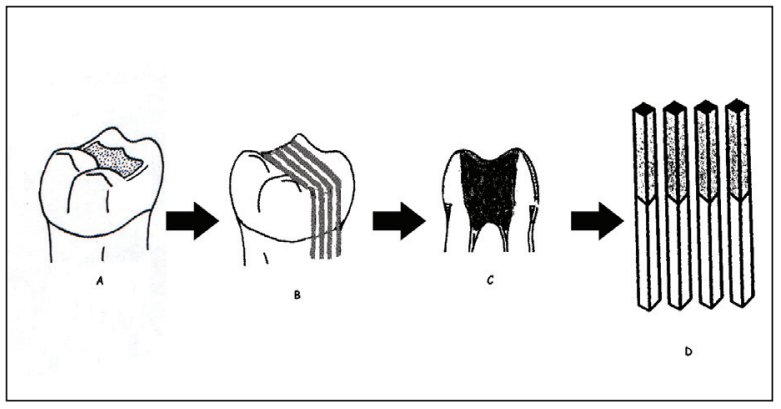

Figure 1. Sample preparation is according to non-trimming method.
Investigations of environmental temperature and relative humidity during the restorative procedure are other relevant clinical aspects. Several previous studies have reported the influence of temperature and relative humidity on early bond strengths of dentin. ${ }^{2,6}$ The presented study was investigated the effect of storage conditions on microtensile bond strength of a self-etching adhesive system.

Spohr et $\mathrm{al}^{7}$ investigated the tensile bond strengths of three adhesive systems (Scotchbond Multi-Purpose, Single Bond and Prime\&Bond NT) applied to dentin at refrigerated or room temperature and reported that no adverse effect was occurred when adhesive systems were used directly from refrigerated storage. In this study, confirming their results, keeping at $4^{\circ} \mathrm{C}$ or $23^{\circ} \mathrm{C}$ room temperature did not effect microtensile bond strength, on the other hand keeping at $40^{\circ} \mathrm{C}$ incubator for one year significantly decreased bond strength $(P<.05)$.

Hagge et $\mathrm{al}^{8}$ investigated the shear bond strength of adhesive systems applied at refrigerated and room temperatures and found no differences between Prime \& Bond and All-Bond 2. On the other hand, shear bond strength of Scotchbond Multi-Purpose was found to be higher at refrigerated temperature (13.14 $\mathrm{MPa}$ ) when compared to room temperature (5.52 $\mathrm{MPa}$ ). They did not offer a satisfactory explanation for the improved bonding ability of refrigerated Scotchbond Multi-Purpose. Self-etch priming systems are generally contain an acidic monomer (MDP), HEMA and water. Temperature could affect the ingredients of these systems. It has been reported that HEMA is hydrolyzed to methacrylic acid and ethylene glycol in acidic conditions, and this hydrolysis is reported to be influenced by the storage temperature. ${ }^{9}$ As

Table 2. Mean values of tensile bond strength (MPa) of CSE Bond to tested pulp chamber dentin (Values with the same letters are not significantly different ( $P>.05)$ ).

\begin{tabular}{ccc}
\hline Groups & N & $\begin{array}{c}\text { Bond Strength Values } \\
\text { (Mean } \pm \text { SD) }\end{array}$ \\
\hline Group 1 & 13 & $29.95 \pm 9.83 \mathrm{a}$ \\
Group 2 & 13 & $29.37 \pm 11.82 \mathrm{a}$ \\
Group 3 & 13 & $27.97 \pm 10.22 \mathrm{a}$ \\
Group 4 & 13 & $17.68 \pm 6.74 \mathrm{~b}$ \\
\hline
\end{tabular}


a matter of fact, results of in this study indicated that keeping the adhesive system in incubator for 1 year reduced the bond strength of the adhesive system $(P<.05)$. However keeping the adhesive system in refrigerator or room temperature did not effect bond strength when compared to the control group ( $P>$.05).

\section{CONCLUSIONS}

The chemical degradation of the adhesive resin due to the high temperature may occur and long term storage could affect bond strength to pulp chamber dentin. According to the results of this study SE Bond adhesive system should be kept in refrigerator until expiry date.

\section{ACKNOWLEDGEMENTS}

This investigation was supported in part by Research center from the Selcuk University Faculty of Dentistry, Turkey.

\section{REFERENCES}

1. Van Meerbeek B, De Munck J, Yoshida Y, Inoue S, Vargas $M$, Vijay $P$ et al. Adhesion to enamel and dentin: current status and future challenges. Oper Dent 2003;28:215-235.

2. Nystrom GP, Holtan JR, Phelps RA, Becker WS, Anderson TB. Temperature and humidity effects on bond strength of a dentinal adhesive. Oper Dent 1998;23:138-143.

3. Nakatsuka K. Modern Trends in Adhesive Dentistry Proceedings of the Adhesive Dentistry Forum 1999. "Characteristics of Clearfil Mega Bond(Clearfil SE Bond)" $1^{\text {st }}$ ed. Yokohama (Japan): Kuraray publishers; 2000.

4. Nakabayashi N, Takarada K. Effect of HEMA on bonding to dentin. Dent Mater 1992;8:125.

5. Shono Y, Ogawa T, Terashita M, Carvalho RM, Pashley EL, Pashley DH. Regional measurement of resin-dentin bonding as an array. J Dent Res 1999;78:699-705.

6. Burrow MF, Taniguchi Y, Nikaido T, Satoh M, Inai N, Tagami $J$ et al. Influence of temperature and relative humidity on early bond strengths to dentine. J Dent 1995;23:41-45.

7. Spohr AM, Sobrinho LC, Consani S, Sinhoreti MAC, Borges $\mathrm{GA}$. Effect of refrigeration on tensile bond strength of three adhesive systems. Braz Dent $J$ 2001;12:75-79.

8. Hagge MS, Lindemuth JS, Broome JC, Fox MJ. Effect of refrigeration on shear bond strength of three dentin bonding systems. Am J Dent 1999;12:131-133.

9. Ogata M. Clinical factors influencing dentin bonding. Degree of Doctor of Philosophy. Tokyo, Japan. 2003. 